\title{
Investigating Rhetorical Aspects of Writing Argumentative Essays and Persuasive Posters: Students' Perspective
}

\author{
Abdelrahman Abdalla Salih \\ College of Arts and Applied Sciences, Dhofar University, Salalah, Sultanate of Oman
}

\begin{abstract}
Students at the tertiary level need arguments because they are expected to use analytical and critical thinking skills. The present study is situated in an English as a Foreign Language (EFL) context in an Omani University and reports the experience of $(\mathrm{N}=46)$ undergraduate $\mathrm{EFL}$ writers in argumentative essays and persuasive posters. Using rhetorical strategies, and drawing on the principles of persuasive writing, the participants prepared posters and essays on two separate topics. Data were collected from the 46 participants' responses to a semi-structured online survey questionnaire. Analysis of the data obtained indicates that the participants preferred designing posters to writing persuasive essays while reporting varieties of rhetorical difficulties in building an argument for persuasion. The participants also perceived establishing evidence and facts as the most challenging element in persuasive writing and arousing the audience's feelings and emotions as the most challenging rhetorical appeal in posters. Some pedagogical implications were reported as well.
\end{abstract}

Index Terms - argumentative writing, persuasive posters, rhetorical appeals, persuasive strategies

\section{INTRODUCTION}

Students in higher education use a variety of genres and writing modes, but the argumentative essay is the most common one (Peloghitis, 2016; Wingate, 2012; Zhu, 2001), probably because it is regarded as an important pedagogical means of building knowledge across a broad range of disciplines (Smith, Kiili, \& Kauppinen, 2016). Arguments are necessary for university students because they are expected to conduct critical analysis of issues, concepts, and situations (Bonnett, 2011; Smalley, Ruetten, \& Kozyrev, 2001). The purpose of argumentative writing, in the second language (L2) instruction context, is to present a viewpoint that is contested or to defend a position (Richards, \& Schmidt, 2002), through evidence and logical presentation of facts. According to Ramage, Bean, and Johnosn (2019), an argument has three essential characteristics: (1) it demands authors and speakers to prove the validity of their claims and statements; (2) it is both a process and a product; and (3) it incorporates components of fact-finding and persuasion. Furthermore, argument incorporates perspectives of rhetoric which is defined as the "study of the ways messages influence people; the faculty of discovering the available means of persuasion in a given case" (Zarefsky, 2005, p. 112). In the wider terrain of argumentative writing, students across disciplines are expected to experience and develop a broader constellation of writing abilities and effective communication skills, specifically persuasion. In the English as a Second Language (ESL)/English as a Foreign Language (EFL) writing context, the use of persuasion is one of the important skills learners of English need to acquire, practice, and master. Learning to develop the ability to communicate effectively and persuasively is essential for students of different programmes in their academic journey and future career, - "an emphasis which is quite appropriate to the L2 classroom" (van Lier, 1988, p. 55). In this regard, Stevens (2005) argues that "Students must learn how to create discourse appropriate to rhetorically persuasive contexts if they are to become successful managers" (p. 62) or perform in any other duties related to their employment. In addition, the innovations in computer-mediated communication which facilitate the rapid proliferation of information via highly advanced media and the Internet have made teaching L2 students to develop argumentative and persuasive skills an important pedagogical goal. It is a pertinent fact that the world today lives in the information era where people are surrounded by multiple sources of information that can be accessed anywhere. Larson (2010), observed that communication media have been important since the printing press - and they continue to be so-but persuasion assumes extra significance in highly technological culture and new media-rich world.

According to Fletcher (2015), teaching persuasion by employing the "rhetorical approach to argumentation" (p.251) incorporates the three conventional rhetorical appeals for ethos, pathos, and logos as identified by Aristotle. According to Lanham (1991), rhetoric seeks persuasion through (1) "ethos, or the demonstration of the speaker's good character, (2) pathos, or playing on the audience's feelings, (3) logos, what today we would call "proof" of some sort" (p.115), or logic. According to Wingate (2012), writing persuasive argumentation involves developing a position, presenting a position, and analyzing and evaluating content knowledge as the key components of argumentation that undergraduate students must learn and practice. Rhetoric is also said to have five canons: (1) invention/discovery, which corresponds to finding what works for the situation, (2) arrangement, or the process of ordering material and structure of content, (3) style, which pertains to language use, (4) memory, which relates to remembering the subject and content of the 
argument, and (5) delivery, which concerns exhausting all the tools and resources available to communicate effectively (Toye, 2013).

Although the argumentative essay is the most common genre students learn to master in higher education, writing argumentative essays with a focus on their rhetorical effects, however, remains a daunting task by nature for many L2 students as it demands them to display their ability to employ sophisticated linguistic and cognitive skills (Campbell, \& Filimon, 2018; Fletcher, 2015). Such a task is expected to be challenging especially for students writing in another language like English (Zhu, 2001). In addition, students were reported to find it difficult to develop their abilities to use persuasive writing due to the inconsistent instruction that overlooked the complexity of the genre itself (Wingate, 2012). The present study attempted to examine higher education students' preferences for persuasive modes, and their experience and difficulties in the argumentative writing process in an EFL writing context. The study specifically attempted to explore students' perceived difficulties in handling the rhetorical appeals for persuasion to build a persuasive argument through argumentative essays and persuasive posters.

\section{LITERATURE REVIEW}

Changing Trends in Writing Discipline Research

The changing scene in university teaching at the dawn of the twenty-first century has challenged many traditional practices, heralding a new era of pedagogic innovations especially in the ESL and EFL writing classrooms. A peculiar feature of the new reality is the relevance and dominance of technology in the entire educational process within the classroom and beyond. This omnipresent medium of learning has passionate users who are described by Prensky (2001) as "digital natives", because "they spent their entire lives surrounded by and using computers, videogames, digital music players, video cams, cell phones, and all the other toys and tools of the digital age" (p.1). Stating the urgent need for technology-contextualized pedagogic activities, particularly in the language classrooms, Shrum and Glisan (2010) argued that "Perhaps the most convincing reason to use technology in teaching languages is the nature of 21 st century students" (p. 449). Considering the changing nature of the learning landscape and the opportunities and challenges it brings, understanding the needs of the digital era learners has become more essential than ever before. According to Delante (2017), "Since technology continues to shape learning in both the real and virtual worlds, universities must remain abreast with technology and be proactive in providing academic learning support to students both for their survival and for student progress" (p.1). In the same vein, Manen and Adams (2009) observed that "in recent years, college and university teachers have been increasingly required to integrate technology in their teaching, and institutions schedule ever more courses online" (p. 10).

Thus, in the context of ESL/EFL writing classrooms, teachers and curriculum designers are required to raise learners' awareness of the significance of technology and facilitate its management and use for better learning in both physical and virtual environments. On the other hand, the coronavirus outbreak has given further significance with convincing evidence to technology-based learning. According to Salih and Omar (2021) "With the disruptive mutations that have affected all countries globally, online education has shifted from being an alternative to a fait accompli, giving little time to academic institutions to consider adopting virtual education as an all-inclusive, one-size-fits-all solution" (p. 62). The pandemic-triggered online education and its practices represent the catalyst for the new direction learning and teaching across disciplines and contexts might take.

On the other hand, the shift of interest in scholarship on the second language (L2) and foreign language (FL) writing instruction from the product-approach to the process-approach has brought new practices to the English Language Teaching (ELT) context with a greater focus on the value of involving the learner in a multidimensional learning situation that offers opportunities for varieties of abilities, competences, and modes of learning various writing genres and styles (Shehadeh, 2011; Villamil \& De Guerrero, 1998). Previous research has attempted to explore the efficacy of collaborative learning activities and peer reviews on the composing process (e.g., Sánchez-Naranjo, 2019; Salih, 2013), as well as the socio-cognitive dimensions of student writers' interaction (Klucevsek, 2016; De Guerrero \& Villamil, 1994; Carson \& Nelson, 1996; Frankenberg-Garcia, 1999). Empirical studies on peer review activities and collaborative learning have also reported significant findings on the role of peer feedback in the writers' revision behaviour and negotiation of meaning (e, g., Yang \& Meng, 2013; Mendonça \& Johnson, 1994), and the social dimensions of peer feedback in shaping writers' drafts in the composing process (Dörnyei, 1997; Flowerdew, 1998). A significant development in the process approach is the growing tendency for integrating the L2 composing process instruction with technology which is witnessing rapid developments in types and applications. The integration of technology into second language classrooms has significant implications for teaching writing genres (Purwanto, 2016; Manen, \& Adams, 2009). Thus, online L2 writing instruction may be most effective when provided as an integral part of a process-oriented environment where L2 writers are offered effective and maximum support to assist them to develop their composing competence (Kuo, 2008). Using technology to integrate and contextualize L2 writing instruction is deemed significant as it appeals to the needs of the digital students and can motivate them to extend their learning activities and continue learning outside the classroom.

This paradigmatic shift in ESL/EFL writing scholarship and practice has gone in tandem with the growing interest in multiple forms of multimodal writing "which combines words, images, sound, and other modes" (Jiang, \& Luk, 2016, p.1), and "asks students to engage in making meaning with a range of new modalities and in new genres" (Miller- 
Cochran, 2017, p. 88). Research in multimodal composing (MC) has attempted to explore its potential in improving the learners' abilities to compose while fulfilling academic tasks (e.g., Lim \& Polio, 2020; Jiang, 2018; Warschauer, 2017), as well as its role in motivating the learners to grasp the target language knowledge and communication skills (Jiang \& Luk, 2016; Manchón, 2017; Yang, 2010). It is believed that "incorporating multiple modalities into an L2 writing classroom can help encourage a focus on process, as various modes of expressions can contribute to invention, drafting, and mixing" (Miller-Cochran, 2017, p. 89).

Calling for incorporating multimodal composing in writing beyond the familiar written essays, Jewitt (2005) argued that integrating technology with instruction means moving beyond the linguistic feature of written forms. The researcher believes that educational practices in the twenty-first century are better enhanced with multimodal composing and that "The multimodal character of new technologies produces a tension for traditional conceptions of literacy that maintain written language at their centre" (p. 330). Shepherd (2018) examined the significance of making connections between the students' previous digital and multimodal experiences and the writing classroom. The author concluded that when students recognize how different writing situations can be related inside and outside the classroom, it is more likely that they will be "convinced that their digital writing experiences have value and the broader definition of writing that includes these experiences will be useful to them" (p.104) in other composing contexts.

Morton-Standish (2014) investigated the use of online media to teach students persuasive writing. According to Morton-Standish, engaging students in online persuasive writing tasks on topics of their interest motivates and enables them to develop argumentative and persuasive skills that can be used in real-life situations. In addition, incorporating online media and engaging students in building online arguments "will develop their persuasive writing in a manner that not only prepares them for the demands of the real world, but imparts the joy and the power that comes with mastering the art of persuasive written expressions" (p. 429). Smith, Kiili, and Kauppinen (2016) compared argumentation in essays and digital videos, as well as the transmission of ideas between them. The researchers reported that the affordances for argumentation offered by each medium were used by the students to transfer meaning as they built an argument. In addition, the distinction between these two mediums provides new insights into the potential for constructing an argument in an educational setting by orchestrating numerous forms. However, it is also significant to examine the students' experience in employing different multimodality to disseminate meaning and build an argument.

Although there is a growing tendency to use technology in contextualizing language learning and teaching and consensus among researchers on the crucial role played by imagery and visuals in arguments, especially when used in conjunction with other modes of communication (Kjeldsen, 2015), the role of multimodality in supporting composing, especially persuasive and argumentative writing, remains peripheral. A possible reason for this is perhaps the fact that multimodality is a relatively new concept and that its theoretical underpinnings are still developing (Stein, 2008).

It is pertinent that there is much current literature in second language writing research that documents argumentative writing in terms of writing processes and strategies used in text production. Researchers have also investigated some aspects of difficulties L2 learners face in argumentative writing. Previous research has attempted to provide insights into the causes of difficulties learners face and the role of teaching strategies and models in identifying challenging areas for students learning persuasive writing. For example, in an action research-based study, Campbell and Filimon (2018) examined the impact of strategy-focused writing techniques on the argumentative-essay writing skills of a linguistically heterogeneous class of 47 students. The researchers found that using strategy-focused writing instruction has helped the students to improve their writing in two aspects, namely, using evidence to build an argument, and the use of standard English. However, the students showed less improvement in the domains of purpose, focus, and structure of argumentative essays. In this context, an understanding of the students' needs and aspects of challenges they may encounter in L2 writing classrooms helps contextualize the writing task and integrate effective instructional strategies. To improve the students' overall writing performance, writing instruction should identify students' difficulties, assign collaborative writing tasks and provide linguistic scaffolding while engaging students in continuous feedback.

Wingate (2012) studied the difficulties undergraduate students encountered while building argumentative essays. The researcher analyzed how 117 first-year undergraduate students conceptualized 'argument' in academic writing and the difficulties they encountered in developing argumentative essays. The researcher found that the students encountered difficulties in writing essays to develop an argument, often due to their lack of understanding of the concept during secondary school, which was aggravated by the inconsistent teaching they received at the university. To help students understand argumentative essay writing, the researcher proposed that argument development should be the primary focus of writing instruction. While helping students to develop the correct and concise understanding of argumentation in academic writing may be an important instructional objective, exploring difficulties with other elements of the writing components remains crucial. In a study about teaching students persuasive writing in business communication, Stevens (2005) found that students are often assigned to write persuasive essays on cases and situations that they have never experienced in real life. The tasks required them to analyze and respond to situations they have never experienced and this complex learning situation created difficulties for those students. The researcher used a personal experience in a car accident to exemplify an authentic real-life situation to teach students strategies for constructing arguments and evidence to the insurance company. They were exposed to the process of building an argument for persuasion by applying the persuasive powers of the rhetorical appeals for ethos, pathos, and logos which help establish credibility, 
stir emotions and build facts and evidence for an argument. The researcher concluded that the students were able to write effective persuasive letters to negotiate the insurance settlements with the insurance company while displaying a level of understanding of the significance of building arguments based on developing clear knowledge about the situation, analyzing the audience, and supporting the purpose of argumentation with evidence. The researcher advocated the use of real-life cases and scenarios to contextualize and integrate building arguments with persuasion instruction.

Grabill (1992), experimented with promoting 37 students' transition from narrative to persuasive writing by asking them to choose an issue of public concern and write a persuasive essay with a specific audience in mind. After completing their essays, the students were asked to convert them to persuasive letters to be sent to the target audience in real-life situations. The students' letters were responded to by the concerned audience. The researcher observed that the students were highly motivated and have shown improved persuasive writing skills and learned to support what was an emotional issue for them and collect evidence and professional opinions. The researcher also reported that students transitioned from an affective, personal writing style to a persuasive one, and, as a result, achieved social interaction. Through their participation in an active public debate, the students developed the essence of authentic persuasive writing.

Peloghitis (2017) studied the difficulties undergraduate Japanese students experienced in writing argumentative essays in English. The researcher found that Japanese students perceived writing the first draft and organizing and structuring ideas as the most challenging aspects, followed by documenting academic sources and implementing citation styles. Students also reported encountering difficulties in initiating thesis statements, counterarguments, grammar, mechanics, word choice, and style while applying varieties of metacognitive strategies, cognitive strategies, social strategies, and rhetorical strategies. In a similar study, Zhu (2001) studied the writing processes, strategies and difficulties faced by 14 Mexican graduate students who were assigned an argumentative writing task in English. The researcher found that the students perceived organization and argumentativeness as the most challenging rhetorical aspects. The researcher also reported that the students developed a variety of self-regulated strategies related to writing processes such as exploring and incorporating feedback, applying writing models, sharing ideas with native speakers, and reflecting on prior knowledge and learning experiences.

Research that investigated the learning of writing in English by EFL Arabic-speaking students has focused mainly on the linguistic and structural challenges facing those students (Abu Rass, 2015; Razak, \& Saeed, 2015), resulting in a limited knowledge of other aspects such as involving learners in the multimodality-enhanced composing processes and the efficacy of incorporating persuasive posters in argumentative essays. In a corpus-based study, Al-Abed Al-Haq, and Ahmed (1994), examined the difficulties Saudi undergraduate students experienced in writing argumentative essays by analyzing 62 essays produced in English by these students. The researchers found that the students were unable to express their thoughts coherently, establish clear arguments through well-written thesis statements, or express their ideas through arguments and counterarguments. The researchers recommended the use of the rhetorical approach instead of the structural approach as well as contrastive rhetoric for teaching L2 students' argumentative and persuasive writing. Although research has explored argumentative writing with depth in recent years, little is known about the pedagogical implications of integrating the rhetorical features of persuasive posters and argumentative writing. Research needs to broaden our understanding of the effective use of the rhetorical aspects of multimodal composing in the context of the argumentative genre and the difficulties learners may encounter in the process. In addition, another area that awaits researchers' attention is studying the role of L2 writers' strategies in handling the rhetorical aspects of multimodal composing.

One of the requisite skills for learners of English is the ability to communicate and persuade effectively. Persuasion is one of the significant soft skills that students need to succeed at the workplace. It is one of the essential graduate attributes many higher education institutions strive to inculcate in their students. Exploring the students' experience in combining posters and essays to build an argument for persuasion is expected to enhance our understanding of the types of challenges these learners have in handling the rhetorical features of argumentative writing. In other words, knowing how L2 students perceive and apply rhetorical devices in their persuasive writing is imperative in any pedagogical effort to help students use and develop better persuasive strategies. The current study attempted to address this issue by examining how L2 undergraduate EFL writers perceived their experience in handling persuasive rhetorical devices to build persuasive essays and posters. Through an analysis of the data obtained from an open-ended survey questionnaire administered to the subjects, the study aimed at answering the following research questions:

1. How do L2 undergraduate students perceive building persuasion through argumentative writing and posters?

2. What aspects of difficulties do L2 students have in writing argumentative essays?

3. How do L2 students perceive incorporating rhetorical devices into building persuasion?

The study's questions were addressed in the following section of methodology.

\section{METHODOLOGY}

The current study is exploratory in nature and combines aspects of qualitative and quantitative methods in its investigation of the students' experience in using rhetorical appeals as strategies to build argumentative essays and persuasive posters. The study examines the participants' perceived difficulties in applying rhetorical appeals in argumentative writing and persuasive posters with a focus on perception rather than production. In other words, the 
study examines learners' difficulties in building persuasive writing from their perspective by building on their inputs rather than examining textual features of their writing process.

\section{A. Context and Task}

The present study was conducted in two EFL learning writing classes in an English Major Programme in an Omani higher learning institution. The two classes had a total enrollment of 46 undergraduate students $(\mathrm{N}=22$ in Group 1 , and $\mathrm{N}=24$ in Group 2) who took a course in Rhetoric (3 Credit Hours) for one full semester which lasted about 16 weeks. The classes for the two groups were scheduled twice a week ( 3 contact hours each) and had four additional contact hours per week. The course aimed at introducing the students to critical and analytical thinking skills by examining classical and modern traditions in rhetoric with focus on essential concepts and perspectives on writing. The syllabus covers a wide range of topics in rhetoric and argumentative writing. The participants were taught about argumentative writing and rhetoric and all topics introduced were geared to offer the students a chance to improve their speaking and writing skills and use language logically, purposefully, and persuasively.

\section{B. Participants}

The participants in the present study were $46 \mathrm{EFL}$ undergraduate students in an Omani higher learning institution. The average age of the participants was 22. They were all native speakers of Arabic and have learned English for at least 15 years. In terms of language proficiency, all the participants had completed the General Foundation Programme after which they joined their English Language and Literature Major. With a good command of English, they are able to follow classes, process ongoing assessment components, and write final exams. To fulfill the assessment criteria of the Course, and after developing reasonable understanding of rhetoric, its purposes of use, as well as aspects of rhetorical strategies and appeals, the students were assigned a writing task in which they were required to work independently and produce a persuasive poster and an argumentative essay (both on the same topic). The first group which comprised 22 students chose tourism as a topic, while the other 24 students in the second group chose the rights for education by individuals with a disability as a topic for their assignment. Both groups were given clear instructions and guidance on the tasks. The students also received regular feedback from the Course Instructor.

\section{Data Collection and Analysis}

\section{Questionnaire Survey}

The purpose of this study was to explore L2 students' difficulties in writing argumentative persuasion. The study used a questionnaire survey as a source of data. After completing and submitting the assignment, the participants were asked to respond to an online debriefing open-ended survey questionnaire about their experience in building argumentative essays and designing persuasive posters with a particular focus on rhetorical appeals. The participants' responses were collected and analyzed by the researcher to determine the difficulties they experience in the rhetorical aspects of argumentative essays. The survey focused on the subjects' understanding of the purpose of argumentative writing and persuasive posters, and the challenges they encountered in applying rhetorical appeals in building an argument. The participants were asked to specify with justifications whether they prefer writing a persuasive essay or designing a persuasive poster as well as the challenges they encountered in building both persuasive essays and persuasive posters. They were also asked to rank the three rhetorical appeals of ethos, logos, and pathos in terms of difficulty by selecting from a four-point scale as 'most challenging', 'challenging', 'less challenging', and 'not challenging'. Administering the open-ended survey with this scale of options was useful as it helped in providing a diagnostic lens and a better understanding of the students' perceptions about the difficulty they encountered with rhetorical appeals. In addition, the analysis of the data elicited from the students' perceived experience in incorporating persuasive posters with argumentative essays provided insights into the pedagogical values of using multimodality in argumentative writing.

\section{RESULTS AND DISCUSSION}

The study's first question explores whether L2 students prefer writing argumentative essays to designing persuasive posters or vice versa. More students in both groups preferred designing persuasive posters to writing argumentative essays. In Group 1 and Group 2 (26 out of 46) students perceived posters as interesting in conveying persuasive messages compared to argumentative essays. On the other hand, 20 students in both groups preferred writing argumentative essays to designing posters. Most participants perceived designing a persuasive poster as easier and more enjoyable than writing an argumentative essay. They described designing persuasive posters as "an attractive", and "good way of persuasion". They also used phrases such as "difficult, demanding, and challenging" to describe writing an argumentative essay task. One of the students is reported to have said, "making a poster is more enjoyable. It takes a tremendous amount of effort to collect and create something unique to send a valuable message. Additionally, people are more likely to notice visuals than words since pictures allow them to comprehend an idea quickly and easily". Another participant said "designing a persuasive poster is more enjoyable. Collecting and creating something out of the box to reach a valuable message is such an amazing work to do. One image is enough to convince the audience by using rhetorical appeals. Furthermore, people tend to catch pictures because they can easily and smoothly get the idea more 
than writing". The participants' interest in using persuasive posters gives a broad hint of their need for better exposure to persuasive writing. It also draws attention to the pedagogical effects and values of incorporating multimodality into persuasive writing. Incorporating persuasive posters into the argumentative essaywriting process provides an important motivational factor that can assist L2 writers to overcome the challenging nature of the argumentative writing process. The values obtained about the students' preferences for rhetorical modes can be seen in Table 1 below.

TABLE 1

FREQUENCY AND PERCENTAGE OF STUdENTS' PREFERENCES FOR RHETORICAL MOdes (N=46)

\begin{tabular}{ll}
\hline Mode & $\%$ \\
\hline Essay & $43(20)$ \\
Poster & $57(26)$ \\
\hline Total & $100(46)$ \\
\hline
\end{tabular}

The other 20 participants expressed their preference of argumentative essays to designing a poster. They perceived writing an argumentative essay as more effective in communicating persuasive messages to the audience, which can make them change their minds or take an action. Comments such as "more persuasive", "carries more evidence", "enables writers to build a persuasive position" were used by the participants to describe writing argumentative essays. One participant said, "I find that writing argumentative essays is more convincing and interesting because it carries more and more evidence, and also more explanation on the subject". Another participant reported that "I think writing a persuasive essay is more interesting because writing a persuasive essay can create more argument through conscious and thoughtful consideration of rhetorical position, audience, and rhetorical appeals, where the audience can be more influenced." Table 2 summarizes the reported common aspects of both argumentative essays and persuasive posters by the participants. These aspects include all the participants' comments and justifications in response to the question about their preferences of writing modes.

TABLE 2

REPORTED ASPECTS OF ESSAYS AND POSTERS ( $\mathrm{N}=46)$

\begin{tabular}{|cl|ll|}
\hline \multicolumn{1}{|c|}{ Essays } & \multicolumn{1}{c|}{ Posters } \\
\hline - & More persuasion power & - & Attractive \\
- & More space for writers to express thoughts & - & Quick delivery of the message \\
- & Enhance other skills & - & Brevity and economy \\
- & Clear elements and structure to follow & - & Wide range of coverage \\
- & Enable social connection & & Can appeal to the audience of different \\
- & Requires evidence to support ideas & - & Touch human emotions \\
- & Relate ideas to purpose & - & Creative \\
- & Deliver direct message & - & Contain precise ideas \\
- & Involve critical thinking & & \\
\hline
\end{tabular}

The use of essay writing and posters for persuasion as combined modes provides a better understanding of how L2 students perceive and understand persuasive writing, as well as the types of difficulties these students have in handling the rhetorical aspects of persuasive writing.

The second research question is about the students' perceived difficulties in writing an argumentative essay. The participants have reported varieties of difficulties they encountered with argumentative essays. The following are the sources of difficulties perceived by the participants:

1. Topic selection

2. Finding evidence

3. Structure/Organization

4. Rhetorical appeals

5. Persuasive strategies

6. Developing an argument/Taking a clear position

7. Rebuttal and counterargument

8. Grammar

9. Audience analysis

10. Appropriate style

11. Topic sentence

12. Title selection

13. Introduction and conclusion

14. Persuasive tone

Most of the participants found difficulty in selecting a topic, structuring and organizing ideas, allocating facts and evidence, and making a clear persuasive argument to win the audience support. One participant said, "I had a hard time at the beginning, which is choosing the appropriate points that should be clarified in writing. I took a long time at this stage". Another student stated that "the main challenge is thinking of the idea...how to arrange all elements in an appropriate way that can influence the reader". The participants also reported other aspects of difficulty concerning the 
selection of appropriate vocabulary, the effective use of rhetorical devices, topic sentences, selecting a catchy title, keeping the audience interested, and the correct use of language. As the data shows, the difficulties reported by the participants provide clear indications of the difficult nature of the argumentative essay writing process for L2 students. Most of these difficulties were reported in the previous literature which investigated difficulties L2 students encounter in argumentative writing. However, it is interesting to see how students perceived related difficulties in establishing persuasive grounds through both writing argumentative essays and persuasive posters. More action research on incorporating multimodal composing into argumentative writing to uncover aspects of difficulties students may have in writing for persuasion is imperative.

The study's third question addresses the participants' perceptions towards the rhetorical devices of ethos, logos, and pathos in building an argument for persuasion in both argumentative essays and posters. The participants $(\mathrm{N}=46)$ were asked to rank the rhetorical appeals according to their level of difficulty starting with the most challenging one. Figure 1 below summarizes the participants' ranking of these rhetorical devices in terms of their level of difficulty in building an argumentative essay. The most challenging rhetorical aspect reported by the participants in writing persuasive essays was to do with providing proof and building facts and evidence for an argument. The strategy of arousing the audience's feelings and emotions by using pathos was ranked second in terms of being most challenging, followed by ethos which deals with the author's credibility. However, the data shows that the participants have ranked pathos first as challenging (37\%), followed by ethos (30\%), and then $\log 0$ s $(11 \%)$. In addition, the data shows that $35 \%$ of the participants perceived ethos as less challenging, while $20 \%$ perceived logos as less challenging and $15 \%$ for pathos. In terms of being easy in writing argumentative essays, 30\% of the participants perceived logos as being easy, and $20 \%$ considered pathos to be so while $15 \%$ perceived ethos as easy. These results shed more light on the difficulties students have with rhetorical appeals in writing argumentative essays.

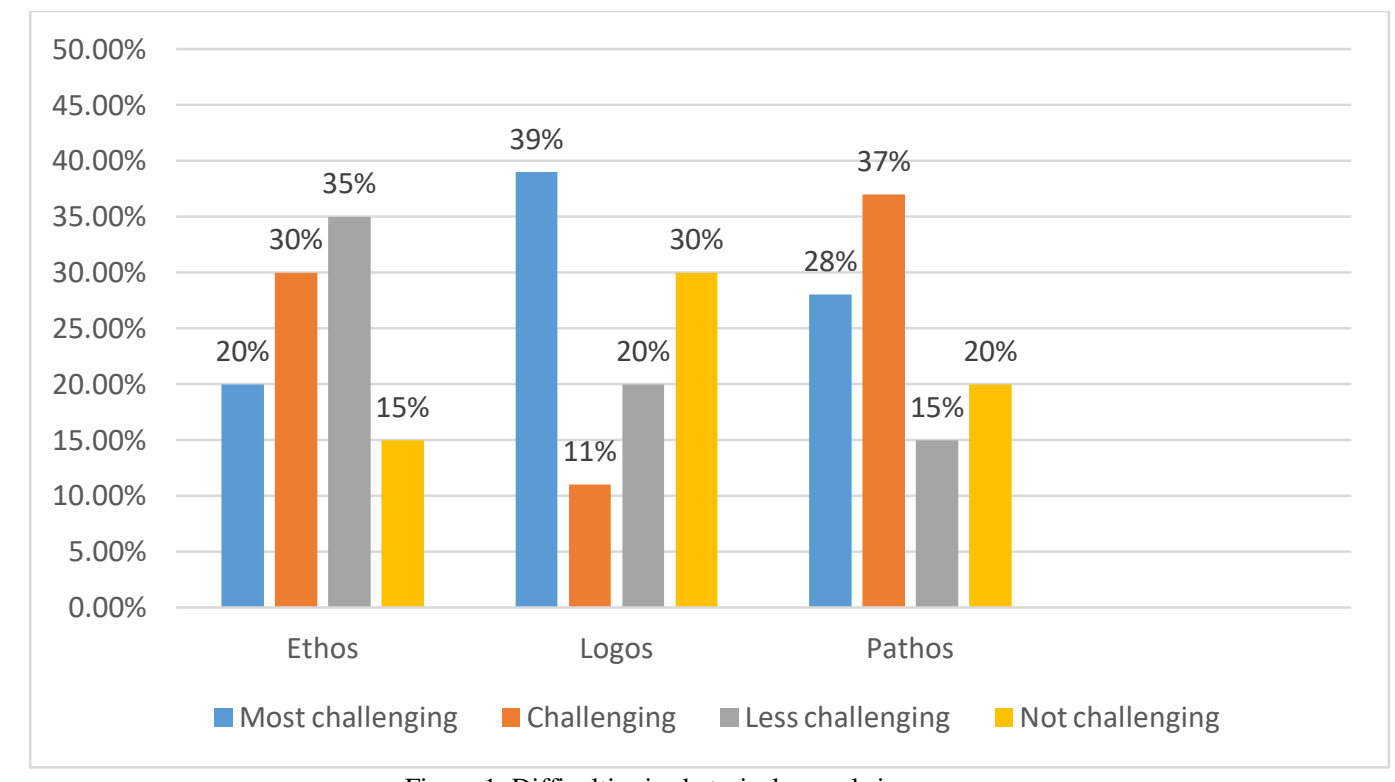

Figure 1. Difficulties in rhetorical appeals in essays

The participants were also asked to report their experience with rhetorical appeals in persuasive posters by ranking the most challenging rhetorical appeal. Figure 2 below summarizes the participants' ranking of these rhetorical devices in terms of their level of difficulty in building persuasive posters. 


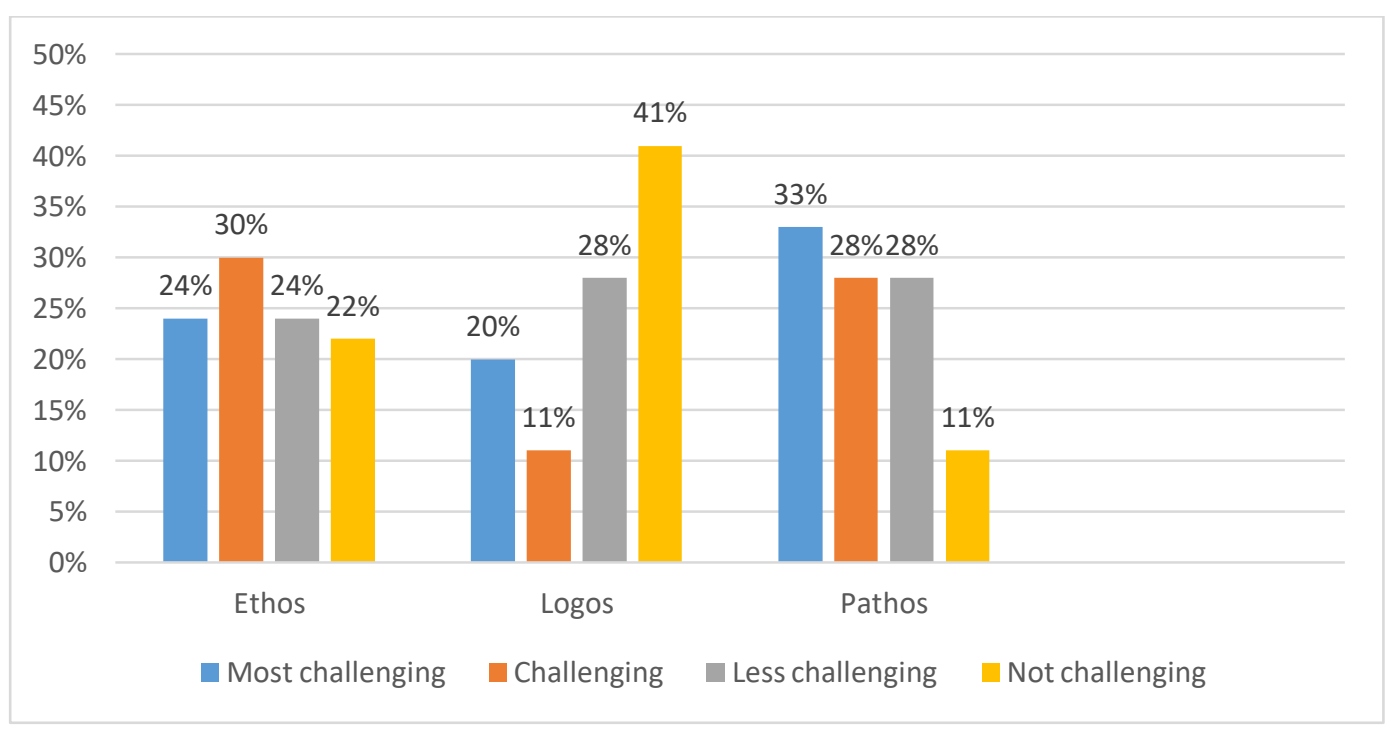

Figure 2. Difficulties in rhetorical appeals in posters

In building persuasion in posters, the participants found pathos the most challenging rhetorical appeal, followed by ethos and then logos. The reported difficulty in persuasive posters concerning building facts and evidence by the participants is consistent with their feedback on the challenges they experienced while establishing logic and proof (logos) in writing persuasive essays. The most challenging common rhetorical appeal for the participants in both argumentative essays and persuasive posters was logos. The process of building facts and providing evidence for an argument is one of the major difficulties L2 students encounter in argumentative writing. However, the participants ranked ethos, which relates to the authors' credibility, first as a challenging rhetorical appeal in persuasive posters followed by pathos and then logos. The students found it difficult to establish credibility and stir the audience's emotions and feelings in persuasive posters as well. This aspect of difficulty is consistent with the reported difficulty in writing argumentative essays about creating persuasion based on facts and evidence and developing strategies to touch the audience's emotions and feelings. Building persuasion in argumentative essays and posters is a task that requires great focus on the audience, and students need to be creative in using persuasive strategies multimodalities such as posters can offer.

The data also reveals that the perceived difficulties in rhetorical devices in both modes showed variation in the way students ranked each device. While the participants reported building facts and evidence for an argument the most difficult element of writing argumentative essays, they found it difficult to stir the audience's feelings and emotions in persuasive posters. Although 57\% of the participants have expressed preferences for posters (see Table 1) in building persuasion, developing persuasion that touches human emotions and motivates action remains a challenge. Students learning to build persuasion in argumentative writing need to understand the different meanings and functions of rhetorical appeals. The results of data analysis in this context reveal an important fact about the features and limitations of multimodality in the context of argumentative writing and persuasion. Research that uncovers the rhetorical aspects of the multimodal composing process in the context of argumentative writing and persuasion is necessary.

\section{CONCLUSION}

The present study explored the difficulties L2 students experienced in argumentative writing and their preferences for argumentative essays and persuasive posters. It was an attempt to understand the aspects of difficulties students encountered when using rhetorical appeals to develop persuasive strategies to communicate their messages in argumentative essays and posters. One of the findings indicates that more participants preferred posters to essay writing as a mode to build an argument for persuasion. This result encourages exploring the use of multimodality such as posters as persuasive modes in teaching students how to construct arguments and use persuasive strategies effectively. The use of persuasive posters within the multimodality context is expected to enrich the students' digital and multimodal composing experience, which can motivate them to relate that to their writing in various contexts. Research that examines the efficacy of incorporating other multimodality genres in building an argument for persuasion is urgent. We need to know if digital multimodal composing can assist L2 students to develop better persuasive strategies that can help them in their real-life situations.

The findings also indicate that the participants found difficulties in certain aspects of writing argumentative essays. The participants reported that they faced challenges in selecting an appropriate topic, organizing and developing the content, establishing facts and evidence as well as establishing an effective tone. The present study's results confirm the findings of previous research that has examined various aspects of difficulties learners had in writing argumentative essays. Students need to be exposed to more text analysis activities, preferably within the collaborative learning context, 
in the writing classrooms and have a better understanding of how to develop persuasive strategies. It is also encouraging to understand the students' experience in using persuasive posters to support building an argument. An important feature of persuasive posters is that they enable users to communicate an idea or a set of ideas and concepts to recipients. The students' perceived difficulties in rhetorical appeals have significant pedagogical values which can inform the L2 classroom writing curriculum and instructional strategies. The rhetorical approach to argumentative writing needs to take into consideration the students' actual knowledge and experience with rhetorical appeals and their affordances as persuasive strategies. In addition, introducing the discourse features of argumentative writing in writing classrooms is better enhanced by action research-based approaches which can provide practical solutions and a better understanding of the classroom reality.

The present study is subject to some limitations. First, it obtained data by focusing on the perceptions of the participants about the difficulties encountered in building an argument rather than the production and the strategies they employed. By examining the students' actual written products, more aspects of difficulties could have been identified. Second, the study could have made use of varied sources of data by interviewing the participants and instructors. Teachers' reports and feedback on the students' performance in writing provide valuable insights into the students' level of knowledge and the challenges they face. The changing nature of learning environments in the 21 st century higher education together with the proliferation of computer-mediated communication and modern media makes changing instructional choices and strategies an inevitable pedagogical step that higher learning institutions have to embrace. Student writers need to be exposed to different persuasive and communicative strategies within multimodal composing practices. More research is needed to uncover these issues.

\section{REFERENCES}

[1] Abu Rass, R. (2015). Challenges face Arab students in writing well-developed paragraphs in English. English Language Teaching, 8(10), 49-59. http://dx.doi.org/10.5539/elt.v8n10p49

[2] Al-Abded Al-Haq, F., \& Ahmed, A.S.E.A. (1994). Discourse problems in argumentative writing. World Englishes, 13(3), 307323. https://doi.org/10.1111/j.1467-971X.1994.tb00318.x

[3] Bonnett, A. (2011). How to argue (3rd Ed.). England: Pearson Education Limited.

[4] Campbell, Y.C., \& Filimon, C. (2018). Supporting the argumentative writing of students in linguistically diverse classrooms: An action research study. Research in Middle Level Education Online, 41(1), 1-10. 10.1080/19404476.2017.1402408

[5] Carson, J., \& Nelson, G. (1996). Chinese students' perceptions of ESL peer response group interaction. Journal of Second Language Writing, 5(1), 1-19. https://doi.org/10.1016/S1060-3743(96)90012-0

[6] De Guerrero, M., \& Villamil, O. (1994). Social-cognitive dimensions of interaction in L2 peer revision. The Modern Language Journal, 78(4), 484-496. https://doi.org/10.1111/j.1540-4781.1994.tb02065.x

[7] Delante, N. L. (2017). Perceived impact of online written feedback on students' writing and learning: a reflection. Reflective Practice, 18(6), 1-33. https://doi.org/10.1080/14623943.2017.1351351

[8] Dörnyei, Z. (1997). Psychological processes in cooperative language learning: group dynamics and motivation. The Modern Language Journal, 81(iv), 482-493. https://doi.org/10.1111/j.1540-4781.1997.tb05515.x

[9] Fletcher, J. (2015). Teaching arguments: Rhetorical comprehension, critique, and response. USA: Stenhouse Publishers.

[10] Flowerdew, L. (1998). A cultural perspective on group work. ELT Journal, 52(4), 323-329. https://doi.org/10.1093/elt/52.4.323

[11] Frankenberg-Garcia, A. (1999). Providing student writers with pre-text feedback. ELT Journal, 53(2), $100-107$. https://doi.org/10.1093/elt/53.2.100

[12] Grabill, P. (1992). Writing the real persuasion. English Journal, 81(8), 60-62. https://doi.org/10.2307/820297

[13] Jewitt, C. (2005). Multimodality, "reading", and "writing" for the 21st century. Discourse: Studies in the Cultural Politics of Education, 26(3), 315-331. https://doi.org/10.1080/01596300500200011

[14] Jiang, L. (2018). Digital multimodal composing and investment change in learners' writing in English as a foreign language. Journal of Second Language Writing, 40, 60-72. https://doi.org/10.1016/j.jslw.2018.03.002

[15] Jiang, L., \& Luk, J. (2016). Multimodal composing as a learning activity in English classrooms: Inquiring into the sources of its motivational capacity. System, 59, 1-11. https://doi.org/10.1016/j.system.2016.04.001

[16] Kjeldsen, J. E. (2015). The Study of visual and multimodal argumentation. Argumentation, 29(2), 115-132. https://doi.org/10.1007/s10503-015-9348-4

[17] Klucevsek, K. (2016). Transferring skills from classroom to professional writing: Student-faculty peer review as an extension of cognitive apprenticeship. Journal of the Scholarship of Teaching and Learning, 16(6), 106-123. https://doi.org/10.14434/josotl.v16i6.20077

[18] Kuo, C. (2008). Designing an online writing system: Learning with support. RELC Journal, 39(3), $285-299$. https://doi.org/10.1177/0033688208096842

[19] Lanham, R. A. (1991). A handlist of rhetorical terms (2nd Ed.). London: University of California Press.

[20] Larson, C. (2010). Persuasion: Reception and responsibility (12th Ed.,). USA: Wadsworth, Cengage Learning.

[21] Lim, J., \& Polio, C. (2020). Multimodal assignments in higher education: Implications for multimodal writing tasks for L2 writers. Journal of Second Language Writing, 47, 1-8. https://doi.org/10.1016/j.jslw.2020.100713

[22] Manchón, R. M. (2017). The potential impact of multimodal composition on language learning. Journal of Second Language Writing, 38, 94-95. https://doi.org/10.1016/j.jslw.2017.10.008

[23] Manen, M., \& Adams, C. (2009). The phenomenology of space in writing online. Educational Philosophy and Theory, 41(1), 10-21. https://doi.org/10.1111/j.1469-5812.2008.00480.x

[24] Mendonça, C., \& Johnson, K. (1994). Peer review negotiations: Revision activities in ESL writing instruction. TESOL Quarterly, 28(4), 745-767. https://doi.org/10.2307/3587558 
[25] Miller-Cochran, S. (2017). Understanding multimodal composing in an L2 writing context. Journal of Second Language Writing, 38, 88-89. https://doi.org/10.1016/j.jslw.2017.10.009

[26] Morton-Standish, L. (2014). Using online media to write extended persuasive text. The Reading Teacher, 67(6), 419-429. https://doi.org/10.1002/trtr.1224

[27] Peloghitis, J. (2017). Difficulties and strategies in argumentative writing: A qualitative analysis. In P. Clements, A. Krause, \& H. Brown (Eds.), Transformation in language education (pp. 399-406). Tokyo: Japan Association for Language Teaching.

[28] Presnsky, M. (2001). Digital natives, digital immigrants, part 1. On the Horizon, 9(5), 1-6. Retrieved July 14, 2021, from https://booksc.org/book/23324988/b5f83c

[29] Purwanto, S. (2016). Improving academic writing skills through online mode of task-based assignments. English Language Teaching, 9(9), 74-84. http://dx.doi.org/10.5539/elt.v9n9p74

[30] Ramage, J. D., Bean, J.C., \& Johnson, J. (2019). Writing arguments: A rhetoric with readings. New York: Pearson.

[31] Razak, N. A., \& Saeed, M. A. (2015). EFL Arab learners' peer revision of writing in a Facebook group: Contributions to written texts and sense of online community, English Language Teaching, 8(12), 11-26. http://dx.doi.org/10.5539/elt.v8n12p11

[32] Richards, J. C., \& Schmidt, R. (2002). Longman dictionary of language teaching and applied linguistics (3rd Ed.). London: Longman Pearson Education.

[33] Salih, A.A. \& Omar, L.I. (2021). Season of migration to remote language learning platforms: Voices from EFL university learners. International Journal of Higher Education, 10(2), pp. 26-73. https://doi.org/10.5430/ijhe.v10n2p62

[34] Salih, A.A. (2013). Peer response to L2 student writing: Patterns and expectations. English Language Teaching, 6(3), $42-50$. http://dx.doi.org/10.5539/elt.v6n3p42

[35] Sánchez-Naranjo, J. (2019). Peer review and training: Pathways to quality and value in second language writing. Foreign Language Annals, 52(3), 612-643. https://doi.org/10.1111/flan.12414

[36] Shehadeh, A. (2011). Effects and student perceptions of collaborative writing in L2. Journal of Second Language Writing, 20(4), 286-305. https://doi.org/10.1016/j.jslw.2011.05.010

[37] Shepherd, R. P. (2018). Digital writing, multimodality, and learning transfer: Crafting connections between composition and online composing. Computers and Composition, 48, 103-114. https://doi.org/10.1016/j.compcom.2018.03.001

[38] Shrum, J. L., \& Glisan, E. W. (2010). Teacher's Handbook: Contextualized language instruction (4th ed.). Heinle Cengage Learning.

[39] Smalley, R. L., Ruetten, M. K., \& Kozyrev, J. R. (2001). Refining composition skills: Rhetoric and grammar (5th Ed.). Australia: Heinle \& Heinle Publishers.

[40] Smith, B. E., Kiili, C., \& Kauppinen, M. (2016). Transmediating argumentation: Students composing across written essays and digital videos in higher education. Computers \& Education, 102, 138-151. https://doi.org/10.1016/j.compedu.2016.08.003

[41] Stein, P. (2008). Multimodal pedagogies in diverse classrooms: representation, rights and resources. London: Routledge.

[42] Stevens, B. (2005). The car accident: An exercise in persuasive writing. Communication Teacher, $19(2)$, 62-67. https://doi.org/10.1080/14704620500123265

[43] Toye, R. (2013). Rhetoric: A very short introduction. Oxford: Oxford University Press.

[44] van Lier, L. (1988). The classroom and the language learner. London: Longman.

[45] Villamil, O. \& De Guerrero, M. (1998). Assessing the impact of peer revision on L2 writing. Applied Linguistics, 19(4), 491514. https://doi.org/10.1093/applin/19.4.491

[46] Warschauer, D. (2017). The pitfalls of multimodal composing. Journal of Second Language Writing, 38, 86-87. https://doi.org/10.1016/j.jslw.2017.10.005

[47] Wingate, U. (2012). 'Argument!' helping students understand what essay writing is about. Journal of English for Academic Purposes, 11(2), 145-154. https://doi.org/10.1016/j.jeap.2011.11.001

[48] Yang, Y. (2010). Students' reflection on online self-correction and peer review to improve writing. Computers \& Education, 55(3), 1202-1210. https://doi.org/10.1016/j.compedu.2010.05.017

[49] Yang, Y. F. \& Meng, W.T. (2013). The effects of online feedback training on students' text revision. Language Learning \& Technology, 17(2), 220-238. http://dx.doi.org/10125/44331

[50] Zarefsky, D. (2005). Argumentation: The study of effective reasoning (2nd Ed.,). USA: The Great Courses.

[51] Zhu, W. (2001). Performing argumentative writing in English: Difficulties, process, and strategies. TESL Canadian Journal, 19(1), 34-50. https://doi.org/10.18806/tesl.v19i1.918

Abdelrahman Abdalla Salih is an Associate Professor of English and Applied Linguistics in the Department of English Language and Literature at Dhofar University, Oman. Prior to this, he has taught English for many years in Malaysia and Sudan. His research and teaching interests include applied linguistics and global English. Salih has published in many peer-reviewed journals including Scopus-indexed and presented at regional, national and international conferences, webinars, and symposia. He is also an active member of many professional bodies and associations. 